\title{
3-week repeated dose oral toxicity study of Clausena excavata extract in ICR mice
}

\author{
Ju-Hyoung Park ${ }^{1} \cdot$ Young-Rak Cho ${ }^{2}$ Young Min Kim² Jae-Shin Kang $^{3}$. \\ Joa Sub Oh ${ }^{1} \cdot$ Eun-Kyung Ahn'
}

\section{ICR 마우스에서 핑크왐피 추출물의 3 주간 반복 투여 독성 연구}

박주형 ${ }^{1}$ - 조영락 ${ }^{2}$. 김영 민 ${ }^{2}$. 강재신 ${ }^{3}$ - 오좌섭 ${ }^{1}$ - 안은경 ${ }^{2}$

Received: 24 December 2018 / Accepted: 28 February 2019 / Published Online: 30 June 2019

(C) The Korean Society for Applied Biological Chemistry 2019

\begin{abstract}
Medicinal herb in Asian countries has been traditionally used for a long time. However, the safety and adverse effect of medicinal herb have not been established yet. The aim of this study is to evaluate toxicity in the oral administration of Clausena excavata (C. excavata) in male ICR mice for 3 weeks and the noobserved adverse effect level (NOAEL). C. excavata has been used as a medicinal herb for the treatment of dermatopathy, malaria, abdominal pain, dysentery, and enteritis. C. excavata was orally administered daily for 21 days at a dose of 100, 250, 500, 1000 , and $2000 \mathrm{mg} / \mathrm{kg} /$ day (MPK). There were no significant differences in mortalities, clinical signs, body weight changes, hematological, and serum biochemistry examination in all animals administrated with $C$. excavate. Consequently, these findings indicated that $C$. excavata did not affect the toxic effect in ICR mice and the NOAEL of $C$. excavata was considered as more than 2000 MPK.
\end{abstract}

Eun-Kyung Ahn $(\bowtie)$

E-mail: aek@gbsa.or.kr

${ }^{1}$ College of Pharmacy, Dankook University, Dandae-ro 119, Dongnam, Cheonan, Chungnam 31116, Republic of Korea

${ }^{2}$ Bio-center, Gyeonggido Business and Science Accelerator, Gwanggyo-ro 147, Yeongtong, Suwon, Gyeonggi 16229, Republic of Korea

${ }^{3}$ Biological Genetic Resources Utilization Division, National Institute of Biological Resources (NIBR), 42 Hwangyeong-ro, Seo-gu, Incheon 404708 , Republic of Korea

This is an Open Access article distributed under the terms of the Creative Commons Attribution Non-Commercial License (http://creativecommons. org/licenses/by-nc/3.0/) which permits unrestricted non-commercial use, distribution, and reproduction in any medium, provided the original work is properly cited.
Keywords 3-week repeated-dose oral toxicity Clausena excavata ICR mouse · No-observed adverse effect level

\section{서 론}

천연물은 전통적으로 한국을 포함한 동양문화권에서 여러 가지 질병을 예방하거나 치료하는 목적으로 오래 전부터 사용되어 왔 다. 최근에는 기능성 식품, 기능성 화장품, 건강보조식품 및 의 약품 개발의 원료로 천연물을 이용하여 활발하게 시도되고 있 다. 서양에서도 천연물을 이용한 대체의학 활용의 증가로 연구 의 필요성은 증가되고 있으며, 천연물 및 생약재의 활성성분 및 효능평가를 위하여 다양한 분석기법이 도입되었다. 이러한 연구 로 얻어진 결과로 천연물 및 생약재가 건강보조식품으로 개발 되고 있다. 하지만, 천연물에는 많은 성분들이 있으며 성분간의 작용에 관해서 알려져 있지 않은 경우가 많다. 전통적으로 오 랜 기간 사용되어 왔다는 사실로 사용되고 있을 뿐, 활발한 활 성연구에 비해 독성 및 안전성 등의 부작용은 과학적인 근거가 부족한 상태이다[1-5]. 핑크왐피(Clausena excavata)는 히말라야, 중국, 말레이시아 반도 및 동남아시아 전역과 같은 아시아 열 대 및 아열대 지역에서 자생하는 야생 식물이다[6,7]. 핑크왐피 는 전통의학에서 복통, 기침, 두통, 비염, 염증, 상처, 발열, 해 독과 같은 치료에 사용하는 것으로 알려져 있다. 핑크왐피 추 출물은 항염증, 항균, 항침착, 면역 조절 및 항산화 작용과 같 은 다양한 생물학적 활성이 보고되었다[8-10]. 이와 같은 핑크 왐피의 다양한 활성은 건강기능성식품 및 의약품 개발에 이용 될 것으로 예상된다. 핑크왐피의 다양한 활용 가능성에도 불구 하고 핑크왐피의 독성이나 부작용을 확인하는 과학적인 시험법 은 찾아보기 어려운 실정이다. 따라서 본 독성 연구는 핑크왐 
피 추출물의 독성반응과 그 안전성을 수컷 ICR 마우스에 3주 간 반복 경구투여 후, 기간 내에 발현되는 독성적 특성을 양적, 질적으로 평가하여 안전성을 확인하였다.

\section{재료 및 방법}

\section{핑크왐피 에탄올 추출물 제조}

핑크왐피(Clausena excavata)는 2017년 6월 환경부 국립생물자 원관으로부터 분양 받았으며, 표본은 (재)경기도경제과학진흥원 바이오센터 천연물연구팀에 보관중이다. 핑크왐피 추출물의 제 조는 상온에서 $50 \%$ 에탄올 $(95 \%$ 발효주정, Samchun chemical) $30 \mathrm{~L}$ 를 건조된 핑크왐피 $50 \mathrm{~kg}$ 에 가하여 3 일씩 2 회 반복 추출 후 여과하였다. 핑크왐피 추출물은 여과된 $50 \%$ 에탄올 여액을 감압 농축(Rotavapor N-1000, Eyela, Tokyo, Japan) 후 동결 건조 (FD8508, Ilshin Lab CO. Ltd., Suwon, Korea)하여 얻었다.

\section{시험물질의 조제 및 투여}

시험물질 보관 냉장고에 보관된 시험물질은 순도에 대한 보정 없이 전자저울로 칭량하여 중량 그대로를 조제에 사용하였고, 정량의 시험물질을 멸균주사용수(중외주사용수, JW중외제약, 서 울, 한국)를 사용하여 교반기로 현탁시켜 $100,250,500,1000$, $2000 \mathrm{mg} / \mathrm{kg}$ (MPK)을 규정 농도로 설정하여 조제하였다. 경구 투여 한계용량으로 가장 많이 사용되는 $2000 \mathrm{MPK}$ 로 설정한 후, 핑크왐피 추출물을 멸균주사용수에 균일하게 용해시켜 조제 하였다. 나머지 시험군 $(1000,500,250$ 및 $100 \mathrm{MPK})$ 은 2배수 간격으로 단계별 희석을 통하여 설정하였다. 핑크왐피 추출물은 경구투여 방법으로 1회/일, 6일/주, 3주간 진행하였고, 조제 후 바로 투여되기 때문에 안정성 시험은 수행하지 않았다[11].

\section{실험동물}

실험동물은 5주령의 특정병원균 부재(Specific Pathogen Free) 수컷 Crl: CD1 (ICR) mouse 를 3주 반복 투여 독성시험을 위해 (주)오리엔트바이오(경기도 성남시 중원구 상대원동 143-1번지)에 서 구입하였다. 실험실에서 1 주일 순화기간 동안 실험동물의 일 반증상을 관찰하여 이상이 없는 실험동물을 선택하여 본 실험 에 사용하였다. 모든 실험동물은 군당 10 마리씩 배치하였다. 시 험 동물 중 ICR계 마우스는 전 세계적으로 독성시험에 널리 사 용되어 왔기 때문에 생리, 해부 및 독성학적 기초자료가 풍부 하여 그 결과를 비교하기가 유리하여 본 시험에 사용하였다.

\section{사육환경}

실험기간 중 사육실 환경조건은 실내온도 $22 \pm 3{ }^{\circ} \mathrm{C}$, 상대습도 $50 \pm 20 \%$, 환기횟수 $15 \sim 20$ 회/h, 조명시간 12 시간(오전 7시 오후 7시) 및 조도 150 300 Lux, 소음 $60 \mathrm{~dB}$ 이하를 유지하였으며 모든 실험동물은 마우스용 polycarbonate 케이지 $(200 \mathrm{~L} \times 260 \mathrm{~W}$ $\times 130 \mathrm{H} \mathrm{mm}$ )에 5 마리씩 분리하여 사육하였다. 본 연구에서의 모든 동물실험은 모든 동물실험은 국제실험동물관리평가인증협 회(AAALAC-I) 완전인증을 받은 (재)경기도경제과학진흥원 바 이오센터에서 동물보호법(제정 1991년 5월 31일 법률 제 4379 호, 일부 개정 2017년 3월 21일 법률 제 4651호)을 근거로 동물 실험윤리위원회(Institutional Animal Care and Use Committee,
IACUC)의 승인(승인번호: 2016-04-0006)하에 표준작업수순서 (Standard Operation Procedures)에 따라 수행하였다.

\section{사료 및 물의 급여방법}

사료(Teklad Certified Irradiated Global 18\% protein Rodent Diet, Harlan Laboratories, Inc., Indianapolis, IN, USA)는 자 율 급이 방식으로 급이기에 넣고 제공하였다. 음수는 $500 \mathrm{~mL}$ 폴리카보네이트 물병에 수돗물을 넣고 자율급수 하였다.

\section{일반중상관찰, 체중 및 사료섭취량 측정}

모든 실험동물은 매일 1 회 이상 일반 상태의 변화, 독성증상 및 사망 동물의 유무를 전 실험 기간 동안 관찰하였다. 체중 측정 은 투여 개시 직전에 1 회, 투여 후 주 2 회씩 3 주간 측정하였으 며, 3주 마지막 체중 측정은 부검 전일에 측정하였다. 사료섭취 량은 투여 개시 전, 투여 개시 후 주 2회 특정하였으며 공급과 동일한 시간대에 잔량을 측정하여 섭취량을 산출하였다[1].

\section{혈액학적 검사}

시험 종료 후 생존한 모든 동물에 대하여 부검 전에 3시간 절 식시키고, 흡입마취제 아이소플로란(Isoflurane)으로 호흡 마취 후 복대정맥으로부터 채혈하여 항응고제인 EDTA가 포함된 채 혈튜브(BD Vacutainer K2E, BD Diagnostics, Franklin Lakes, $\mathrm{NJ}$, USA)에 넣고 30 분간 교반 후, $\mathrm{CBC}$ 분석기(BECKMAN COULTER AcT diff, Fullerton, CA, USA)를 이용하여 white blood cell count (WBC), red blood cell count (RBC), hemoglobin concentration (HGB), hematocrit (HCT), mean corpuscular volume (MCV), mean corpuscular hemoglobin $(\mathrm{MCH})$, mean corpuscular hemoglobin concentration (MCHC), platelet (PLT)를 검사하였다[12].

\section{혈액생화학적 검사}

복대정맥으로 채혈한 실험동물의 혈액 $1 \mathrm{~mL}$ 을 $3,000 \mathrm{rpm}, 15$ 분 간 원심분리기(Centrifuge 5415R, Eppendorf, hamburg, Germany) 를 이용하여 혈장 $300 \mu \mathrm{L}$ 를 얻었다. 원심 분리하여 얻은 혈장 을 자동생화학분석기(7020, HITACHI, Tokyo, Japan)를 이용하 여 glucose (GLU), creatinine (CREA), total protein (TP), albumin (ALB), glutamate oxaloacetate transaminase (GOT), glutamate pyruvate transaminase (GPT), total bilirubin (T-BIL), direct bilirubin (D-BIL), total cholesterol, triglyceride (TG), high density lipoprotein (HDL), blood urea nitrogen (BUN), low density lipoprotein (LDL), inorganic phosphorous (IP), lactate dehydrogenase $(\mathrm{LDH})$ 를 측정하였다[13].

\section{부검}

시험 종료 후 모든 생존동물을 흡입마취제 아이소플로란 (Isoflurane)으로 호흡 마취 후 복대정맥에서 혈액을 채취한 후, 복대정맥을 절단하여 방혈시켜 육안으로 외부소견, 피하, 복강 장기, 흥강장기 및 뇌에 대하여 검사하였다[14].

\section{통계 처리}

본 시험에서 확인된 결과는 one-way analysis of variance (ANOVA) 분석을 통하여 평균 \pm 표준편차로 나타내었다. 유의성이 인정될 
경우 Student's t-test (Microsoft Excel)를 실시하여 대조군과 시험군 간의 통계학적 유의성을 검정하였다 $(p<0.01$ 와 $p<0.05)$.

\section{결 과}

\section{일반중상}

핑크왐피 추출물의 3주간 투여기간 동안 시험물질의 영향으로 보이는 일반증상은 관찰되지 않았다. 또한 대조군을 포함한 모 든 시험군에서 유의할 만한 이상증상과 사망동물은 없었다.

\section{체중변화와 사료섭취량}

3 주간의 핑크왐피 추출물 투여기간 동안 체중측정결과 대조군 과 비교하여 모든 실험동물에서 대조군과 유사한 정상적인 체 중증가가 관찰되었다(Fig. 1). 핑크왐피 추출물의 투여로 체중의 유의성 있는 변화는 관찰되지 않았다. 시험기간 동안 핑크왐피 추출물 투여로 인한 사료섭취량은 유의성 있는 변화는 관찰되 지 않았다(Fig. 2). 모든 시험군의 사료섭취량은 정상군과 유사 한 사료섭취량이 관찰되었다.

\section{혈액학적 검사}

3 주간 핑크왐피 추출물을 반복 투여한 후, 복대정맥에서 채혈한 혈액으로 $\mathrm{WBC}, \mathrm{RBC}, \mathrm{HGB}, \mathrm{HCT}, \mathrm{MCV}, \mathrm{MCH}, \mathrm{MCHC}$, $\mathrm{PLT}$ 를 분석하였다(Table 1). 핑크왐피 추출물 $1000 \mathrm{MPK}$ 과 $2000 \mathrm{MPK}$ 투여군에서 대조군과 비교하여 $\mathrm{WBC}$ 가 감소하는 경 향을 보였다. 그러나 백혈구의 감소하는 범위가 크지 않았고 일 반증상과 다른 임상병리학적 검사에서 백혈구의 감소와 연관지 을 수 있는 소견이 발견되지 않았다. $\mathrm{WBC}$ 를 제외한 항목에서 는 대조군과 핑크왐피 추출물을 농도별로 투여한 모든 군의 결 과는 통계적인 유의성을 관찰 할 수 없었다.

\section{혈액생화학적검사}

3 주간 핑크왐피 추출물을 반복 투여한 후, 복대정맥에서 채혈한 혈액에서 분리한 혈청을 이용하여 간기능(GOT, GPT, LDH, $\mathrm{ALB}, \mathrm{TP}, \mathrm{T}-\mathrm{BIL}, \mathrm{D}-\mathrm{BIL})$, 신장기능(BUN, $\mathrm{CRE})$, 지질영양 관 련(TCHO, TG), 전해질(I.P) 관련 지표들을 분석하였다(Table 2). 대조군과 농도별 핑크왐피 추출물을 투여한 모든 군의 결과 는 대부분의 항목들에서 통계적 유의성을 관찰 할 수 없었다 (Table 2). 그러나 대조군과 비교하여 GOT 수치가 $100 \mathrm{MPK}$ 에서 유의하게 증가하였고, $\mathrm{TG}$ 수치가 핑크왐피 추출물 250 MPK 에서 유의하게 증가하였다. GLU 수치는 핑크왐피 추출 물 $1000 \mathrm{MPK}$ 를 제외하고 통계적으로 유의하게 증가하였다. 간 기능 지표인 T-BIL과 D-BIL 그리고 전해질 지표인 I.P에서 통 계적으로 유의하게 감소하였다. 일부 항목에서 통계적으로 유의 하게 증가하고 감소하는 결과가 나타났지만, 정상 범위 내에서 의 증가와 감소로 핑크왐피 추출물의 투여에 의한 변화는 아닌 것으로 판단된다.

\section{고 찰}

핑크왐피 추출물의 다양한 활성은 많이 보고가 되었으나, 독성

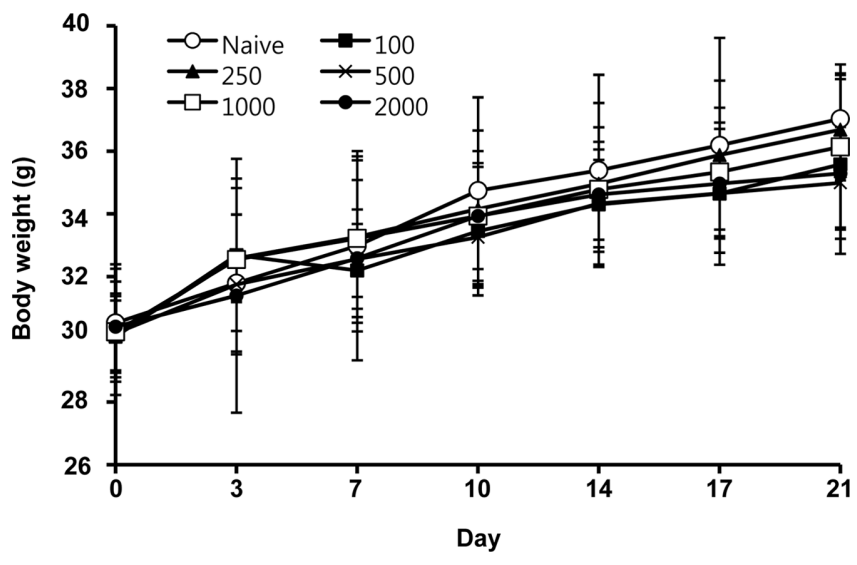

Fig. 1 Change in body weight of male ICR mouse during oral administration treated with $C$. excavata extract for 21 days. $\bigcirc$, naive; C. excavata $100 \mathrm{mg} / \mathrm{kg} ; \boldsymbol{\Delta}$, C. excavata $250 \mathrm{mg} / \mathrm{kg} ; \times$, C. excavata 500 $\mathrm{mg} / \mathrm{kg} ; \square$, C. excavata $1000 \mathrm{mg} / \mathrm{kg} ;$, C. excavata $2000 \mathrm{mg} / \mathrm{kg}$

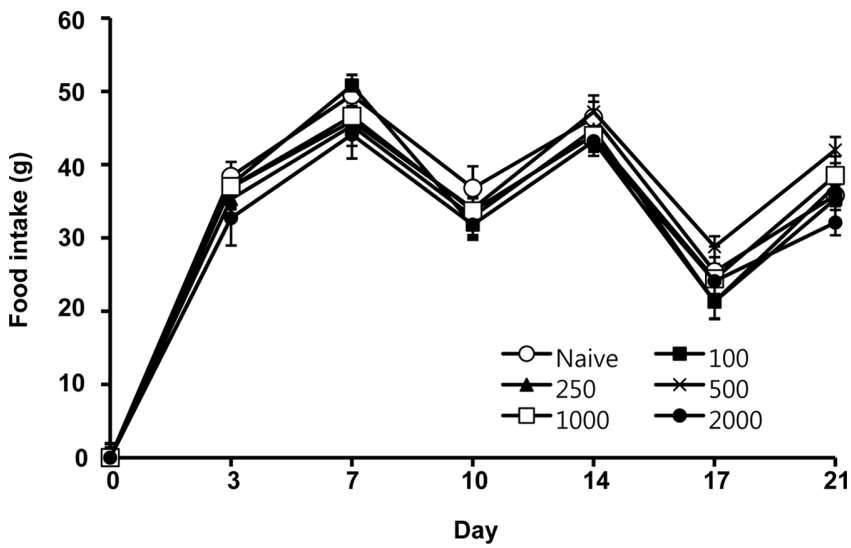

Fig. 2 Food intake of male ICR mouse treated with $C$. excavate extract for 21 days. $\bigcirc$, naive; $\boldsymbol{\square}$, C. excavata $100 \mathrm{mg} / \mathrm{kg} ; \boldsymbol{\Delta}$, C. excavata 250 $\mathrm{mg} / \mathrm{kg} ; \times$, C. excavata $500 \mathrm{mg} / \mathrm{kg} ; \square, C$. excavata $1000 \mathrm{mg} / \mathrm{kg} ; \bigcirc, C$. excavata $2000 \mathrm{mg} / \mathrm{kg}$

및 안전성에 관한 연구 결과는 비교적 찾아보기 어렵다. 따라 서 본 연구는 3 주간 핑크왐피 추출물의 반복 경구투여로 독성 시험이 진행되었다. 독성시험은 대조군을 포함하여 100,250 , 500,1000 , 및 $2000 \mathrm{MPK}$ 투여군으로 설정하였다. 핑크왐피 추 출물의 3주 반복 경구투여 후, 일반증상, 무게변화, 혈액학적 및 혈액생화학적 검사를 하였다. 혈액생화학적 검사 중 일부 평가 항목(GOT, TG, GLU, T-BIL, D-BIL, I.P)에서 대조군과 비교 하여 증가와 감소하는 경향을 보였다. GLU의 증가는 용량의존 성이 없었으며, 간기능과 관련된 GOT, GPT, T-BIL, D-BIL이 용량의존적으로 증가하지 않았으므로 간독성과 같은 독성학적 의미는 없는 것으로 판단된다. T-BIL, D-BIL, I.P의 일정한 증 가 또는 감소 경향이 동반되지 않았으므로 시험물질투여에 의 한 독성과의 명확한 연관성을 없었다. 이러한 변화는 핑크왐피 추출물의 투여로 인한 영향이 아닌 경미한 변동으로서 정상 범 위 내에서의 변화로 간주되어진다. 대조군을 포함한 모든 투여 군에서 특별한 이상증상은 나타나지 않았고, $2000 \mathrm{MPK}$ 이상 
Table 1 Hematological analysis of male ICR mouse treated with C. excavata extract for 21 days

\begin{tabular}{|c|c|c|c|c|}
\hline Parameters & WBC $\left(10^{3} / \mathrm{uL}\right)$ & $\mathrm{RBC}\left(10^{6} / \mu \mathrm{L}\right)$ & HGB (g/dL) & HCT $(\%)$ \\
\hline Naïve & $6.23 \pm 1.32$ & $8.18 \pm 0.73$ & $13.33 \pm 0.47$ & $39.50 \pm 4.39$ \\
\hline $100 \mathrm{MPK}$ & $7.08 \pm 1.48$ & $7.82 \pm 0.55$ & $13.20 \pm 0.81$ & $40.05 \pm 2.33$ \\
\hline $250 \mathrm{MPK}$ & $7.18 \pm 0.69$ & $7.70 \pm 0.29$ & $13.15 \pm 0.96$ & $40.25 \pm 3.66$ \\
\hline $500 \mathrm{MPK}$ & $6.40 \pm 0.65$ & $7.88 \pm 0.61$ & $13.13 \pm 0.96$ & $39.70 \pm 2.12$ \\
\hline 1000MPK & $5.40 \pm 0.53$ & $7.09 \pm 0.62$ & $12.30 \pm 1.22$ & $37.10 \pm 3.29$ \\
\hline 2000MPK & $5.54 \pm 1.23$ & $7.52 \pm 0.32$ & $12.90 \pm 0.61$ & $38.54 \pm 1.65$ \\
\hline Parameters & MCV (fL) & MCH (pg) & $\mathrm{MCHC}(\mathrm{g} / \mathrm{dL})$ & PLT $\left(10^{3} / \mu \mathrm{L}\right)$ \\
\hline Naïve & $48.20 \pm 1.25$ & $16.20 \pm 0.84$ & $33.80 \pm 2.57$ & $952.30 \pm 238.70$ \\
\hline 100MPK & $51.38 \pm 4.04$ & $16.90 \pm 1.03$ & $32.98 \pm 0.86$ & $789.70 \pm 379.30$ \\
\hline $250 \mathrm{MPK}$ & $52.23 \pm 3.78$ & $17.08 \pm 1.09$ & $32.70 \pm 0.61$ & $861.00 \pm 251.90$ \\
\hline $500 \mathrm{MPK}$ & $50.50 \pm 2.13$ & $16.70 \pm 0.29$ & $33.10 \pm 0.87$ & $849.00 \pm 390.10$ \\
\hline 1000MPK & $52.33 \pm 2.14$ & $17.37 \pm 0.58$ & $33.20 \pm 0.52$ & $739.70 \pm 278.40$ \\
\hline 2000MPK & $51.30 \pm 1.91$ & $17.16 \pm 1.00$ & $33.44 \pm 1.03$ & $1021.70 \pm 147.10$ \\
\hline
\end{tabular}

Values are presented as the means \pm standard deviations. WBC; white blood cell count, RBC; red blood cell count, HGB; hemoglobin concentration, HCT; hematocrit, MCV; mean corpuscular volume, MCH; mean corpuscular hemoglobin, MCHC; mean corpuscular hemoglobin concentration, PLT; platelet

Table 2 Serum biochemical analysis of male ICR mouse treated with C. excavata extract for 21 days

\begin{tabular}{|c|c|c|c|c|c|}
\hline Group/Item & GOT & GTP & $\mathrm{LDH}$ & T.CHO & HDL \\
\hline Unit & $\mathrm{U} / \mathrm{L}$ & $\mathrm{U} / \mathrm{L}$ & $\mathrm{U} / \mathrm{L}$ & $\mathrm{mg} / \mathrm{dL}$ & $\mathrm{mg} / \mathrm{dL}$ \\
\hline Naïve & $67.16 \pm 12.21$ & $28.25 \pm 7.04$ & $259.41 \pm 66.79$ & $142.11 \pm 32.14$ & $79.71 \pm 17.18$ \\
\hline $100 \mathrm{MPK}$ & $87.97 \pm 9.61^{*}$ & $28.28 \pm 1.07$ & $405.32 \pm 138.68$ & $159.90 \pm 13.15$ & $87.16 \pm 1.40$ \\
\hline 250MPK & $94.39 \pm 22.61$ & $29.74 \pm 5.81$ & $443.76 \pm 155.50$ & $174.36 \pm 11.87$ & $98.02 \pm 9.63$ \\
\hline 500MPK & $90.41 \pm 9.91$ & $27.97 \pm 4.73$ & $430.21 \pm 71.06$ & $184.18 \pm 5.56$ & $102.90 \pm 3.86$ \\
\hline 1000MPK & $69.74 \pm 15.46$ & $27.18 \pm 4.07$ & $491.60 \pm 197.83$ & $165.68 \pm 15.73$ & $93.64 \pm 7.70$ \\
\hline 2000MPK & $49.40 \pm 5.83$ & $26.69 \pm 6.26$ & $225.09 \pm 44.08$ & $164.10 \pm 25.50$ & $96.51 \pm 15.26$ \\
\hline Group/Item & LDL & TG & GLU & $\mathrm{TP}$ & ALB \\
\hline Unit & $\mathrm{mg} / \mathrm{dL}$ & $\mathrm{mg} / \mathrm{dL}$ & $\mathrm{mg} / \mathrm{dL}$ & $\mathrm{g} / \mathrm{dL}$ & $\mathrm{g} / \mathrm{dL}$ \\
\hline Naïve & $5.11 \pm 1.62$ & $87.81 \pm 34.78$ & $242.03 \pm 5.69$ & $4.45 \pm 0.43$ & $1.49 \pm 0.15$ \\
\hline 100MPK & $6.42 \pm 2.41$ & $98.97 \pm 21.01$ & $368.24 \pm 29.11 * *$ & $4.77 \pm 0.16$ & $1.59 \pm 0.04$ \\
\hline 250MPK & $6.63 \pm 1.10$ & $152.09 \pm 24.03 *$ & $488.50 \pm 30.41 * *$ & $4.97 \pm 0.31$ & $1.63 \pm 0.08$ \\
\hline $500 \mathrm{MPK}$ & $7.00 \pm 1.29$ & $148.47 \pm 31.91$ & $496.87 \pm 48.66^{* *}$ & $4.98 \pm 0.31$ & $1.65 \pm 0.06$ \\
\hline 1000MPK & $7.70 \pm 1.46$ & $68.92 \pm 9.61$ & $310.66 \pm 51.40$ & $4.83 \pm 0.15$ & $1.62 \pm 0.06$ \\
\hline 2000MPK & $7.07 \pm 2.66$ & $116.27 \pm 36.94$ & $420.61 \pm 43.87 * *$ & $5.10 \pm 0.20$ & $1.71 \pm 0.09$ \\
\hline Group/Item & T-BIL & D-BIL & BUN & IP & CREA \\
\hline Unit & $\mathrm{mg} / \mathrm{dL}$ & $\mathrm{mg} / \mathrm{dL}$ & $\mathrm{mg} / \mathrm{dL}$ & $\mathrm{mg} / \mathrm{dL}$ & $\mathrm{mg} / \mathrm{dL}$ \\
\hline Naïve & $0.23 \pm 0.03$ & $0.13 \pm 0.01$ & $22.25 \pm 1.67$ & $13.31 \pm 0.89$ & $0.44 \pm 0.07$ \\
\hline 100MPK & $0.15 \pm 0.03 *$ & $0.10 \pm 0.01 *$ & $24.54 \pm 3.64$ & $10.49 \pm 1.20^{*}$ & $0.49 \pm 0.06$ \\
\hline $250 \mathrm{MPK}$ & $0.14 \pm 0.03 *$ & $0.08 \pm 0.02 *$ & $24.33 \pm 3.89$ & $10.08 \pm 0.97^{*}$ & $0.45 \pm 0.05$ \\
\hline $500 \mathrm{MPK}$ & $0.10 \pm 0.03^{* *}$ & $0.07 \pm 0.02 *$ & $22.95 \pm 2.08$ & $9.77 \pm 0.56^{*}$ & $0.41 \pm 0.03$ \\
\hline 1000MPK & $0.09 \pm 0.02 * *$ & $0.06 \pm 0.02 *$ & $28.51 \pm 5.88$ & $8.51 \pm 0.51^{* *}$ & $0.52 \pm 0.04$ \\
\hline 2000MPK & $0.10 \pm 0.03^{*}$ & $0.06 \pm 0.03^{*}$ & $26.49 \pm 2.11$ & $10.30 \pm 0.98^{*}$ & $0.52 \pm 0.04$ \\
\hline
\end{tabular}

Values are presented as the means \pm standard deviations. GOT; glutamate oxaloacetate transaminase, GPT; glutamate pyruvate transaminase, LDH; lactate dehydrogenase, T.CHO; total cholesterol, HDL; high density lipoprotein, LDL; low density lipoprotein, TG; triglyceride, GLU; glucose, TP; total protein, ALB; albumin, T-BIL; total bilirubin, D-BIL; direct bilirubin, BUN; blood urea nitrogen, IP; inorganic phosphorous, CREA; creatinine. $*_{p}<0.05$ : Significantly different from the naive by Student's t-test. ${ }^{*} p<0.01$ : Significantly different from the naive by Student's t-test 
에서 최대무독성용량이 판단된다. 본 연구 결과는 핑크왐피의 과학적 안전성의 기초자료로 사용될 수 있을 것이다. 이후에 추 가적인 독성시험에 관한 연구가 진행된다면, 건강 기능성 식품 및 의약품과 같은 다양한 소재로 핑크왐피의 활용이 있을 것으 로 사료된다.

Acknowledgment 본 연구과제는 환경부 국립생물자원관(NIBR No. 201906-203)의 지원으로 수행되었으며 이에 감사드립니다.

\section{초 록}

핑크왐피는 피부병, 말라리아, 복통, 이질 및 장염 치료를 위한 약용 식물로 사용되고 있다. 본 연구의 목적은 핑크왐피의 안 전성을 확인하기 위하여, 수컷 ICR 마우스를 이용하여 핑크왐 피를 3주 반복 경구 투여하여 최대무독성용량을 평가했다. 핑 크왐피를 $100,250,500,1000$, 및 $2000 \mathrm{mg} / \mathrm{kg}$ 으로 투여한 결 과, 모든 시험물질 투여군에서 이상이 관찰되지 않았다. 사망률, 임상 증상, 체중 변화, 혈액 학적 검사 및 혈청 생화학 검사에 서 유의적인 차이는 없었고, 경미한 변동은 핑크왐피의 투여로 인한 영향이 아닌 정상 범위 내에서의 변화로 간주 되어진다. 결과적으로, 핑크왐피는 모든 시험물질 투여군에서 독성 영향을 미치지 않았으며, 핑크왐피의 최대무독성용량은 $2000 \mathrm{mg} / \mathrm{kg}$ 이 상으로 간주되었다.

Keywords ICR 마우스 · 3주간 반복 투여 독성 평가 · 최대무독 성용량 - 핑크왐피

\section{References}

1. Lee JE, Kim HJ, Choi EK, Chai HY, Yun YW, Kim DJ, Nam SY, Lee BJ, Ahn B, Kang HG, Kim YB (2003) Four-week repeated-dose toxicity study on Pinellia Extract. Korean J Lab Anim Sci 19: 127-141
2. Na CS, Hong CY, Na DS, Kim JB, Yoon SY, Lee SB, Dong MS (2013) Hotwater extract of Hovenia dulcis peduncle improves exercise performance and anti-fatigue effect in mice. Kor J Pharmacogn 44: 8390

3. Um MY, Ha TY, Seong KS, Kim YS (2013) In vitro screening of the acetylcholinesterase inhibition, anti-oxidant activity, and neuronal cell protective effect of medicinal plant extracts. Korean J Food Preserv 20: 840-845

4. Yoon HJ, Choe MS, Cho HJ, Han BS, Park KH, Oh JA, Cho NJ, Paik MK (2014) Study of kidney toxicity of Azadirachta indica extract for oral administration in rats. Korean J Environ Agric 33: 103-110

5. Hwang IY, Hwang SA, Jeong CS (2013) Effects of Kalopanax pictus extracts and their related origin on gastric lesions. J Fd Hyg Safety 28: 367-375

6. Manosroi A, Saraphanchotiwitthaya A, Manosroi J (2003) Immunomodulatory activities of Clausena excavata Burm. $f$. wood extracts. J Ethnopharmacol 89: 155-160

7. Sharif NWM, Mustahil NA, Mohd Noor NS, Sukari MA, Rahmani M, Taufiq-Yap YH, Ee GCL (2011) Cytotoxic constituents of Clausena excavata. Afr J Biotechnol 10: 16337-16341

8. Rahman MT, Alimuzzaman M, Shilpi JA, Hossain MF (2002) Antinociceptive activity of Clausena excavata leaves. Fitoterapia 73: 701-703

9. Kumar R, Saha A, Saha DA (2012) New antifungal coumarin from Clausena excavata. Fitoterapia 83: 230-233

10. Guntupalli C, Kumar GS, Kumar AS, Tubati T (2012) Evaluation of antioxidant activity of the methanolic leaf extract of Clausena excavata Burm. f. (Rutaceae) using the lipid peroxidation model. Pharmacogn J 4: 22-25

11. Yoo JG, Jung JY (2012) Studies on the repeated toxicity test of food red No.2 for 4 weeks oral administration in SD Rat. J Fd Hyg Safety 27: 4249

12. Kim YB, Hong DH, Cho ES, Lm WJ, Kim IH, Son HY (2014) Effect of repeated Paecilomyces japonica treatment on rats. Korean J Vet Res 54: 31-38

13. Lee JS, Lee JS, Park YC, Choi SM, Lee SH (2014) A repeated-dose 28day oral toxicity test of Aconitum jaluense extract in sprague-dawley rats. Yakhak Hoeji 58: 62-70

14. Roh HS, Seok JH, Jeong JY, Lee JK, Kim TS, Choi HK, Ha HY (2014) Repeated dose oral toxicity study of Alismatis rhizoma in SD Rats. J Korean Med Ophthalmol Otolaryngol Dermatol 27: 7-90 